\title{
EXTRATO HIDROALCOÓLICO DE Erythrina crista-galli L. FRENTE A MICRORGANISMOS CAUSADORES DA MASTITE BOVINA
}

\author{
Gabriela Berguenmaier de Olanda ${ }^{1}$, Gilberto Antônio Peripolli Bevilaqua ${ }^{2}$, Luiz \\ Filipe Damé Schuch ${ }^{3}$, Luciana Souza Prestes ${ }^{4}$, Ricardo Batista Job ${ }^{5}$ \\ ${ }^{1}$ Doutoranda do PPG em Sistemas de Produção Agrícola Familiar da Universidade \\ Federal de Pelotas (gabiolanda@hotmail.com), Pelotas, RS, Brasil. \\ ${ }^{2}$ Dr. Pesquisador da EMBRAPA Clima Temperado, Estação Experimental Terras \\ Baixas, Pelotas, RS, Brasil. \\ ${ }^{3}$ Dr. Professor da Faculdade de Veterinária da Universidade Federal de Pelotas, \\ Pelotas, RS, Brasil. \\ ${ }^{4}$ Dra. Veterinária, Pelotas, RS, Brasil. \\ ${ }^{5}$ Doutorando do PPG em Sistemas de Produção Agrícola Familiar da Universidade \\ Federal de Pelotas, Pelotas, RS, Brasil.
}

Recebido em: 03/10/2016 - Aprovado em: 21/11/2016 - Publicado em: 05/12/2016 DOI: 10.18677/EnciBio_2016B 049

\section{RESUMO}

O uso de plantas medicinais na prevenção e tratamento da mastite bovina é uma prática eficiente, principalmente quando todo o manejo é baseado nos princípios da produção de base ecológica. A espécie arbórea Erytrina crista-galli L., pertencente à família Fabaceae, nativa do Brasil e de outros países da América Latina, apresenta efeito medicinal reconhecido por sua ação antibacteriana, antimalarial e antioxidante. Sendo assim, o objetivo deste trabalho foi avaliar o efeito do extrato hidroalcoólico da casca de E. crista-galli sobre microrganismos promotores da mastite bovina. A metodologia utilizada foi a microdiluição em calda e as concentrações utilizadas do extrato hidroalcoólico foram $50 \%, 25 \%, 12,5 \%$ e $6,25 \%$. Como resultados, o extrato apresentou efeito inibitório sobre os microrganismos Escherichia coli, Pseudomonas aeroginosa, Staphylococcus aureus, Staphylococcus hyicus, Streptococcus intermedius e Streptococcus uberis.

PALAVRAS-CHAVE: agroecologia, corticeira do banhado, plantas medicinais.

\section{HYDROALCOHOLIC EXTRACT ERYTHRINA CRISTA-GALLIL. FACE TO MICROORGANISMS CAUSING THE BOVINE MASTITIS}

\begin{abstract}
The use of medicinal plants in the prevention and treatment of bovine mastitis is an efficient practice, especially when the entire management is based on the principles of ecological production base. The arboreal species Erytrina crista-galli L., belonging to the family Fabaceae, native to Brazil and other Latin American countries, has medicinal effect recognized for its antibacterial, antimalarial and antioxidant. Thus, the aim of this study was to evaluate the effect of hydroalcoholic extract of $E$. cristagalli on microorganisms promoters of bovine mastitis. The methodology used was the microdilution syrup and the concentrations used hydroalcoholic were $50 \%, 25 \%$, $12,5 \%$ and $6,25 \%$. As a result, the extract showed inhibitory effect on the
\end{abstract}


microorganisms Escherichia coli, Pseudomonas aeruginosa, Staphylococcus aureus, Staphylococcus hyicus, Streptococcus intermedius and Streptococcus uberis.

KEYWORDS: agroecology, cork the plated, medicinal plants.

\section{INTRODUÇÃO}

A mastite bovina, causada por agentes bacterianos e leveduras, mostra-se como uma das principais doenças infecciosas da produção leiteira, sendo que inúmeros fármacos e desinfetantes convencionais vêm promovendo resistência aos microrganismos (CAMPOS et al., 2014). A produção animal em sistemas de base ecológica, que possui como princípios o bem-estar animal e o cuidado do planeta como um todo, está em ascensão no Brasil, principalmente pelo ativismo de movimentos pró-ecologia, que vêm pressionando produtores e empresas dedicados a produção animal (FIGUEIREDO, 2002).

No contexto da produção de leite nesses sistemas, a obtenção de leite em quantidade e qualidade, deve solucionar as questões sanitárias através de alternativas sustentáveis entre os recursos naturais renováveis, onde o uso das plantas medicinais mostra-se com grande potencial ( $\mathrm{SCHUCH}$ et al., 2008). Dessa forma, estudos científicos já vêm demostrando que o uso da fitoterapia na veterinária tem logrado grandes êxitos no tratamento de várias enfermidades de bovinos, suínos, ovinos, caprinos, aves, peixes e répteis (SANTANA et al., 2015).

O uso de fitoterápicos na prevenção e tratamento da mastite bovina, principal enfermidade da produção leiteira, vem sendo utilizado por muitos agricultores e veterinários, através de soluções ou pomadas medicinais à base de ervas para uso tópico ou via oral com plantas verdes e secas (SCHUCH et al., 2008). Nesse cenário, evidencia-se que várias espécies do gênero Erytrina, da família Fabaceae, apresentam propriedades medicinais (GILBERT \& FAVORETO, 2012). Entre elas, a espécie Erytrina crista-galli L., árvore nativa do Brasil, Uruguai, Paraguai, leste da Bolívia e Argentina, com ocorrência em ambientes úmidos e florestas de galerias (MELLO et al., 2015) é reconhecida por sua ação antibacteriana (VIVOT et al., 2012) antimalarial e antioxidante (TJAHJANDARIE et al., 2014), onde os principais constituintes são alcaloides (OZAWA et al., 2010) e flavonoides (ASHMAWY et al., 2016).

Diante do exposto, o objetivo do trabalho foi avaliar o efeito de diferentes diluições do extrato hidroalcoólico da casca de E. crista-galli frente a diferentes microrganismos promotores da mastite bovina.

\section{MATERIAL E MÉTODOS}

A casca de E. crista-galli foi coletada no mês de fevereiro, no ano de 2009, na área da Estação Experimental Terras Baixas, EMBRAPA Clima Temperado, Estação Experimental Terras Baixas, nas coordenadas 3148'5 8"S e 5228'1"O. O material coletado foi seco em temperatura ambiente, até que o mesmo se mostrou quebradiço a pressão exercida pelos dedos. Em seguida, preparou-se o extrato hidroalcoólico na proporção 1:10, ou seja, $100 \mathrm{~g}$ de casca triturada para um litro de álcool de cereais $70^{\circ} \mathrm{GL}$. O material permaneceu ime rso no álcool por um período de 15 dias, em vidro âmbar, com duas agitações diárias. Após, procedeu-se a coagem, com auxílio de gases e a solução foi armazenada no mesmo vidro no escuro, até o momento do uso no experimento. 
Neste momento, extraiu-se o solvente álcool com auxílio de evaporador rotativo, com $30 \mathrm{RPM}, 50^{\circ} \mathrm{C}$ e pressão negativa de $600 \mathrm{~mm} / \mathrm{Hg}$ e por fim completouse o volume inicial da solução com água destilada estéril. As diluições utilizadas no experimento foram $50 \%, 25 \%, 12,5 \%$ e $6,25 \%$.

Para a avaliação da atividade antibacteriana foi realizada a técnica de microdiluição em calda, em microplacas de 96 orifícios em triplicata, a fim de ser determinada a concentração bactericida mínima (CBM).

Os microrganismos testados foram Escherichia coli ATCC, Pseudomonas aeruginosa ATCC, Salmonella ATCC, Staphylococcus aureus ATCC, Staphylococcus aureus, Staphylococcus hyicus, Streptococcus agalactiae, Streptococcus dysgalactiae, Streptococcus intermedius e Streptococcus uberis, armazenados no Laboratório de Doenças Infecciosas da Universidade Federal de Pelotas (UFPel). Os inóculos foram preparados na concentração $10^{-5}$ UFC. $\mathrm{mL}^{-1} \mathrm{em}$ meio contendo solução salina e caldo BHI 2x (brain heart infusion).

Nas microplacas, foram colocados o extrato de casca de E. crista-galli e os inóculos das bactérias, além do controle de crescimento das bactérias e o controle extrato. Em seguida, as microplacas foram incubadas por 72 horas em estufa a temperatura de $37^{\circ} \mathrm{C}$. Após esse período, alíquotas de $5 \mu \mathrm{L}$ de cada orifício foram transferidas para placas contendo meio Ágar sangue desfibrinado de equino à $5 \% \mathrm{e}$ mantidos em incubação por 24 horas, na mesma temperatura anterior, para a leitura do crescimento das bactérias.

Os resultados do trabalho foram expressos em porcentagem de Concentração Bactericida Mínima. Para isso, foi realizada a média geométrica das menores concentrações do extrato da planta, das três repetições, capaz de inibir o crescimento bacteriano a partir das alíquotas transferidas para o Ágar sangue (GONÇALVES et al., 2013).

\section{RESULTADOS E DISCUSSÃO}

Os resultados da Concentração Bactericida Mínima (CBM) do extrato hidroalcoólico de E. crista-gali, para cada microrganismo, estão apresentados na tabela 1.

TABELA 1: Concentração Bactericida Mínima (CBM) do extrato hidroalcoólico de Erythrina crista-galli L. determinada pelo método de microdiluição em calda.

MICRORGANISMOS

Escherichia coli ATCC
Pseudomonas aeruginosa ATCC
Salmonella ATCC
Staphylococcus aureus ATCC
Staphylococcus aureus
Staphylococcus hyicus
Streptococcus agalacteae
Streptococcus dysgalacteae
Streptococcus intermedius
Streptococcus uberis

Escherichia coli ATCC

Pseudomonas aeruginosa ATCC

Salmonella ATCC

Staphylococcus aureus ATCC

Staphylococcus aureus

Staphylococcus hyicus

Streptococcus agalacteae

Streptococcus dysgalacteae

Streptococcus uberis
CBM (\%)

25

50

Resistente*

12,5

Resistente*

25

Resistente*

Resistente*

25

25

${ }^{*}$ Resistente: sem ação bactericida. 
Entre os microrganismos testados, o que se mostrou mais sensível ao extrato de E. crista-galli foi $S$. aureus ATCC na concentração de 12,5\%, não sendo este mesmo efeito observado para a outra cepa do mesmo microrganismo, que se justifica pela possível resistência do mesmo. Nesse sentido, VIVOT et al. (2012) também observaram diferença no efeito do extrato de $E$. crista-galli frente a diferentes cepas de $S$. aureus.

Já os microrganismos E. coli ATCC, S. hyicus, S. intermedius e S. uberis apresentaram sensibilidade na metade da dose do extrato de E. crista-galli em comparação a $P$. aeroginosa ATCC, que foi a $50 \%$. Sendo que, os demais microrganismos não foram afetados pelo extrato em nenhuma das doses.

Nesse sentido, VIVOT et al. (2012), ao avaliarem diferentes extratos de espécies medicinais da Argentina sobre os microrganismos Bacillus subtilis, $P$. aeruginosa, $S$. aureus e E. coli evidenciaram que o extrato metanólico e etanólico da casca e o extrato etanólico das folhas de E. crista-galli foram eficientes sobre $B$. subtilis e $S$. aureus.

Resultados relevantes, sobre a ação antimicrobiana, são encontrados para outras espécies do gênero Erythrina. Onde, AKTER et al. (2016) ao testarem a ação de extrato da casca de Erytrina stricta Roxb., obtiveram efeito inibitório sobre $S$. aureus e Candida albicans e TANAKA et al. (2011) sobre S. aureus ao analisarem a raiz de Erythrina variegata $\mathrm{L}$.

Também, DJEUSSI et al. (2015) ao avaliarem compostos brutos da folha e casca de Erythrina sigmoidea Hua. sobre as bactérias gram-negativas E. coli (ATCC8739, AG100, AG100A, AG100A aerogenes (ATCC13048, CM64, EA27, EA289, EA294, EA298), Enterobacter cloacae (ECCl69, BM47, BM67), Klebsiella pneumoniae (ATCC12296, KP55, KP63, K24, K2), Providencia stuartii (NEA16, ATCC29916, PS2636, PS299645) e P. aeruginosa (PA01, PA124) evidenciaram inibição no crescimento de 26 das 27 bactérias testadas, ou seja, 96,3\%. Já, PICHARDO et al. (2014) demostraram que extratos com os solventes: água, hexano e acetona de raiz de Erythrina herbacea L. foram eficientes sobre $S$. aureus e E. coli.

Ademais, outras espécies de plantas vêm sendo avaliadas com esse viés. MOTA et al. (2013), ao estudarem diferentes concentrações dos extratos hidroalcoólicos de folha fresca e seca de Syzygium cumini (L.) Skeels sobre microrganismos causadores da mastite bovina, evidenciaram as menores porcentagens de concentrações inibitória mínima (CIM) para o extrato com folhas frescas para S. uberis, S. agalacteae, S. dysgalacteae, S. aureus e Staphyococcus coagulase (-), que para o extrato com folhas secas se deu para Staphylococcus. coagulase (+), E. coli e $P$. aeruginosa, sendo que estes dois últimos mostraram-se resistentes para o extrato de folhas frescas. MELLO-PEIXOTO et al. (2014) ao avaliarem as concentrações de 4,2, 1, 0,5, 0,25, 0,125 e $0,0625 \mathrm{mg} / \mathrm{mL}$ do extrato hidroalcoólico da casca de Punica granatum Linn. sobre diferentes espécies de Staphylococcus isoladas de leite bovino, observaram ação inibitória sobre $S$. aureus, $S$. coagulase negativa e $S$. saprophyticus.

GARCIA et al. (2011) ao analisarem extratos etanólicos de casca de Hymenaea courbaril L., da planta inteira de Bidens pilosa L., da casca de Psidium guajava L. e das folhas de Pothomorphe umbellata (L.) Miq., obtiveram resultados positivos sobre S. aureus. Já, FACCIN et al. (2016) concluíram que o extrato hidroalcoólico de Schinus terebinthifolius Raddi pode ser utilizado de forma alternativa ao iodo na 
assepsia dos tetos bovinos na ordenha, pois a concentração de $20 \%$ do extrato em pré e pós dipping, por um período de 12 semanas, não diferenciou-se do tratamento com iodo.

Dessa forma, observa-se que o uso das plantas medicinais para o manejo na produção leiteira é uma possibilidade real e viável, que deve ser utilizada de forma complementar a outros elementos, os quais corroboram com a saúde animal.

\section{CONCLUSÃO}

O extrato hidroalcoólico de Erythrina crista-galli, nas condições desse trabalho, apresentou efeito inibitório sobre os microrganismos $E$. coli, $P$. aeroginosa, $S$. aureus, S. hyicus, $S$. intermedius e $S$. uberis.

\section{REFERÊNCIAS}

AKTER, K.; BARNES, E.C.; LOA-KUM-CHEUNG, W.L.; YIN, P.; KICHU, M.; BROPHY, J.J.; BARROW, R.A.; IMCHEN, I.; VEMULPAD, S.R.; JAMIE, J.F. Antimicrobial and antioxidant activity and chemical characterisation of Erythrina stricta Roxb. (Fabaceae). Journal of Ethnopharmacology, v.185, n.5, p.171-181, 2016. 10.1016/j.jep.2016.03.011

ASHMAWY, N.S.; ASHOUR, M.L.; WINK, M.; EL-SHAZLY, M.; CHANG, F.; SWILAM, N.; ABDEL-NAIM, A.B.; AYOUB, N. Polyphenols from Erythrina crista-galli: structures, molecular docking and phytoestrogenic activity. Molecules, v.21, n.726, p.1-14, 2016. Disponível em: <http://www.mdpi.com/1420-3049/21/6/726> doi: 10.3390/molecules21060726

CAMPOS, F.L.; VALENTE, P.; AVANCINI, C.A.M. Higiene em saúde e produção animal na agroecologia: avaliação da atividade de extrações de plantas consideradas medicinais no sul do Brasil para uso como desinfetante e antisséptico frente agentes causais transmissíveis em mastite micótica bovina. Cadernos de Agroecologia, v.9, n.2, p1-2, 2014. Disponível em: <http://www.abaagroecologia.org.br/revistas/index.php/cad/article/view/15840/10016>

DJEUSSI, D.E.; SANDJO, L.P.; NOUMEDEM, J.A.K.; OMOSA, L.K.; NGADJUI, B.T.; KUETE, V. Antibacterial activities of the methanol extracts and compounds from Erythrina sigmoidea against Gram-negative multi-drug resistant phenotypes. BMC. Complementary and Alternative Medicine, v.15, n.453, p.1-7, 2015. Disponível em: <http://bmccomplementalternmed.biomedcentral.com/articles/10.1186/s12906015-0978-8> doi: 10.1186/s12906-015-0978-8

FACCIN, A.; SCHUCH, L.F.D.; SCHIAVON, D.B.A.; GONÇALVES, C.L.; MOTA, F.V.; LESSA, L.F. Use of hydroalcoholic extract of Schinus Terebinthifolius Raddi in pre- and post-milking antisepsis of the teat in dairy cows. Ciência Animal Brasileira, v.17, n.1, p.90-97, 2016. Disponível em: $<$ http://www.scielo.br/scielo.php?script=sci_arttext\&pid=S180968912016000100090 > doi: 10.1590/1089-6891v17i123998 
GONÇALVES, C.L.; SCHUBERT, R.N.; FACCIN, A.; MOTA, F.V.; SCHUCH, L.F.D. Óleo essencial de murta (Blepharocalyx salicifolius (Kunth) O. Berg) como alternativa no tratamento de mastite bovina. Revista Cadernos de Agroecologia, v.8, n.2, p.14, 2013. Disponível em: <http://www.abaagroecologia.org.br/revistas/index.php/cad/article/view/14408/9622>

FIGUEIREDO, E.A.P. Pecuária e agroecologia no Brasil. Cadernos de Ciência \& Tecnologia, v.19, n.2, p.235-265, 2002. Disponível em: $<$ http://ainfo.cnptia.embrapa.br/digital/bitstream/item/86810/1/pecuaria-eagroecologia.pdf>

GARCIA, C.S.; UEDA, S.M.Y.; MIMICA, L.M.J. Avaliação da atividade antibacteriana in vitro de extratos hidroetanólicos de plantas sobre Staphylococcus aureus MRSA e MSSA. Revista do Instituto Adolfo Lutz, v.70, n.4, 2011. Disponível em: $<$ http://periodicos.ses.sp.bvs.br/scielo.php?script=sci_arttext\&pid=S007398552011000400022\&lng=pt\&nrm=iso=pt>

GILBERT, B.; FAVORETO, R. Monografia: Erythrina sp. Fabaceae (Leguminosae, Faboideae). Revista Fitos, v.7, n.3, p.185-197, 2012. Disponível em: <http://revistafitos.far.fiocruz.br/index.php/revista-fitos/article/viewFile/152/150>

MELLO-PEIXOTO, E.C.T.; MOREIRA, G.M.B.; MATSUMOTO, L.S.; SILVA, R.M.G.; DOMINGUES, P.F. Extrato hidroalcoólico de Punica granatum Linn. sobre Staphylococcus spp. isolado de leite bovino. Cadernos de Agroecologia, v.9, n.1, $2014 . \quad$ Disponível em: <http://www.abaagroecologia.org.br/revistas/index.php/cad/article/view/15492/10064>

MELLO, L.M.; REINIGER, L.R.; MENEGHELLO, G.E.; VILLELA, F.A.; MOTA, M.S. Isolamento de DNA genômico a partir de folhas e câmbio congelados de Erythrina cristagalli L., FABACEAE (Corticeira-do-banhado). Revista Thema, v.12, n.2, p.8293, $2015 . \quad$ Disponível em: <http://revistathema.ifsul.edu.br/index.php/thema/article/view/281> doi: 12.2015.8293.281

MOTA, F.V.; SCHUCH, L.F.D.; GONÇALVES, C.L.; FACCIN, A.; SCHIAVON, D.B.A.; BOHM, B.C.; LESSA, L.F. Actividad antibacteriana de los extractos de Syzygium cumini (L.) Skeels (jambolán) frente a los microorganismos asociados a la mastitis bovina. Revista Cubana de Plantas Medicinais, v.18, n.3, p.495-501, 2013. Disponível em: <http://scielo.sld.cu/scielo.php?script=sci_arttext\&pid=S102847962013000300016>

OZAWA, M.; KAWAMATA, S.; ETOH, T.; HAYASHI, M.; KOMIYAMA, K.; KISHIDA, A.; KURODA, C.; OHSAKI, A. Structures of new erythrinan alkaloids and nitric oxide production inhibitors from Erythrina crista-galli. Chemical Pharmaceutical Bulletin, v.58, n.8, p.1119-1122, 2010. Disponível em: <https://www.jstage.jst.go.jp/article/cpb/58/8/58_8_1119/_pdf> doi: $10.1248 / \mathrm{cpb} .58 .1119$

PICHARDO, C.O.; GARCÉS, R.C.; VILLAFRANCO, M.E.L.; GARZA, M.G.; ARRIAGA-ALBA, M. Estudio de mutagenicidad y actividad antibacteriana de 
Erythrina herbacea, Zanthoxylum caribaeum y Dendropanax arboreus. Revista Mexicana de Ciências Farmacéuticas, v.45, n.1, p.78-85, 2014. Disponível em: < http://www.scielo.org.mx/scielo.php?pid=S1870-

01952014000100009\&script=sci_arttext>

SANTANA, D.C.; SOUZA, T.S.; PIERRO, P.C.C.; AMARAL, A.A. Uso de plantas medicinais na criação animal. Enciclopédia Biosfera, v.11, n.22, p.226-241, 2015. Disponível em: <http://www.conhecer.org.br/enciclop/2015E/uso\%20de\%20plantas.pdf>

SCHUCH, L.F.D.; WIEST, J.M.; COIMBRA, H.S.; PRESTES, L.S.; TONI, L.; LEMOS, J.S. Cinética da atividade antibacteriana in vitro de extratos naturais frente a microrganismos relacionados à mastite bovina. Ciência Animal Brasileira, v.9, n.1, p.161-169, 2008.2 Disponível em: <http://www.revistas.ufg.br/vet/article/view/968/3442>

TANAKA, H.; ATSUMI, I.; SHIROTA, O.; SEKITA, S.; SAKAI, E.; SATO, M.; MURATA, J.; MURATA, H.; DARNAEDI, D.; CHEN, I. Three new constituents from the roots of Erythrina variegata and their antibacterial activity against methicillinresistant Staphylococcus aureus. Chemistry \& Biodiversity, v.8, n.3, p.476-482, 2011. Disponível em: <http://www.ncbi.nlm.nih.gov/pubmed/21404431> doi: 10.1002/cbdv.201000068

TJAHJANDARIE, T.S.; PUDJIASTUTI, P., SAPUTRI, R.D.; TANJUNG, M. Antimalarial and antioxidant activity of phenolic compounds isolated from Erythrina crista-galli L. Journal of Chemical and Pharmaceutical Research, v.6, n.4, p.786790, 2014. Disponível em: <https://www.researchgate.net/publication/269400077>

VIVOT, E.P.; SÁNCHEZ, C.; CACIK, F.; SEQUIN, C. Actividad antibacteriana en plantas medicinales de la flora de Entre Ríos (Argentina). Ciencia, Docencia y Tecnología, v.23, n.45, p.165-185, 2012. Disponível em: $<$ http://www.scielo.org.ar/scielo.php?script=sci_arttext\&pid=S1851$17162012000200008>$ 